\title{
Patient-Focused Selection of PrEP Medication for Individuals at Risk of HIV: A Narrative Review
}

Sheldon D. Fields · Elyse Tung

Accepted: December 9, 2020 / Published online: February 10, 2021

(C) The Author(s) 2021

\begin{abstract}
Pre-exposure prophylaxis (PrEP) medication is a key component of the HIV prevention strategy in the US, which has been demonstrated to be highly effective in preventing HIV acquisition among individuals at risk. Two PrEP medications are currently approved: emtricitabine/ tenofovir disoproxil fumarate $\left(\right.$ Truvada $^{\circledR}$; F/TDF) was approved by the US Food and Drug Administration in 2012, followed by emtricitabine/tenofovir alafenamide $\left(\right.$ Descovy $^{\circledR}$; $\mathrm{F} / \mathrm{TAF}$ ) in 2019. An ongoing randomized, double-blind, Phase 3 study (DISCOVER) demonstrated that F/TAF had non-inferior efficacy to F/TDF. While both medications have been found to be efficacious and well tolerated, several studies have identified that important differences exist with regards to pharmacokinetics, bone and renal safety profiles, and other factors. In this narrative review, we conducted a comprehensive evaluation of the populations at risk of HIV who may also be affected by, or at risk of, bone or renal conditions. We reviewed the safety profiles of F/TDF and F/TAF to develop an evidence-based algorithm for selecting the
\end{abstract}

\section{S. D. Fields ( $\square)$}

The Pennsylvania State University, College of

Nursing, University Park, PA, USA

e-mail: sdf5275@psu.edu

E. Tung

Kelley-Ross Pharmacy, Seattle, WA, USA appropriate PrEP medication, based on biological, behavioral, and health characteristics of an individual at risk of HIV, and considered how the choice of PrEP medication may or may not compound safety concerns for these individuals. We identified that the introduction of $\mathrm{F} / \mathrm{TAF}$ provides a valuable alternative to F/TDF, allowing the personalization of PrEP. F/TAF may be the preferred medication for cisgender men and transgender women at risk of HIV infection who are predisposed to, or already have, bone or renal conditions. While the approval of F/TAF is the first step in personalization of PrEP, additional options are still warranted to help accommodate the wide spectrum of individuals at risk of HIV with different lifestyles, medical histories, preferences, and requirements.

\section{PLAIN LANGUAGE SUMMARY}

Pre-exposure prophylaxis (or PrEP) prevents HIV acquisition in individuals at risk of HIV infection. There are currently two approved options for PrEP in the US; both are oral medications. The first option, approved in 2012, is a combination of two drugs called emtricitabine/tenofovir disoproxil fumarate-also known as Truvada $^{\circledR}$ or F/TDF. The second option, approved in 2019 , is a combination of emtricitabine and a different prodrug, tenofovir 
alafenamide-this combination is called Descovy $^{\circledR}$ or F/TAF. Both options are 99\% effective in preventing HIV if taken daily. While the risk of serious side effects from taking either of the PrEP medications is low, F/TAF has demonstrated less effect on bone and kidney health, and may be the preferred option in people with bone or kidney conditions, or in those at risk of developing osteoporosis or having risk factors for kidney disease, such as people living with diabetes or high blood pressure. As the risk of HIV sometimes overlaps with risks to bone and renal health according to race/ethnicity, poverty, alcohol/substance use, smoking tobacco, and taking other medications, F/TAF as an alternative PrEP medication allows the PrEP choice to depend on the broader health conditions of the individual. 'Personalized medicine' means that medicines can be chosen to suit an individual's biology, behavior, lifestyle, and overall health. The approval of F/TAF is the first step in personalization of PrEP medication, while additional options need to be researched to meet the requirements of all individuals at risk of HIV.

Keywords: Bone; Decision making; HIV prevention; Kidney; Personalized medicine; Pre-exposure prophylaxis; Preference; Renal; Tenofovir alafenamide; Tenofovir disoproxil fumarate

\section{Key Summary Points}

There are currently two approved options for HIV pre-exposure prophylaxis (PrEP) in the US: emtricitabine/tenofovir disoproxil fumarate (Truvada ${ }^{\circledR} ; \mathrm{F} / \mathrm{TDF}$ ) and emtricitabine/tenofovir alafenamide (Descovy ${ }^{\circledR} ;$ F/TAF).

F/TDF and F/TAF have differences in pharmacokinetics as well as renal and bone safety profiles.
Candidates for PrEP medication, who are at risk of HIV, often have additional risks of developing bone or renal comorbidities, due to a variety of factors, including race/ethnicity, diet, alcohol/substance use, tobacco smoking, concomitant medications, and/or other lifestyle factors.

Due to its more favorable safety profile, F/TAF may be the preferred choice for cisgender men and transgender women at risk of HIV, who are also at risk of developing bone or renal conditions; F/TDF may be the preferred choice in individuals at risk of HIV who are cisgender women or are at risk of HIV through receptive vaginal sex.

The more favorable safety profile of $\mathrm{F} / \mathrm{TAF}$ is particularly advantageous during the ongoing global COVID-19 pandemic, as it may reduce the need for individuals to attend clinics in person.

Future PrEP options are warranted to allow for improved personalization to accommodate the various needs of individuals at risk of HIV.

\section{DIGITAL FEATURES}

This article is published with digital features, including a summary slide and plain language summary, to facilitate understanding of the article. To view digital features for this article go to $\quad$ https://doi.org/10.6084/m9.figshare. 13353098

\section{INTRODUCTION}

More than a million individuals in the US are living with HIV [1]. In recent years, pre-exposure prophylaxis (PrEP) medication for individuals who are HIV negative but at risk of acquiring HIV has become an important 
method of HIV prevention and a key part of the overall plan for ending the HIV epidemic in the US [2-4]. PrEP has been shown to be highly effective in preventing HIV in both clinical trials and real-world studies, with the estimated effectiveness dependent on adherence [5-8]. A positive real-world impact of PrEP on HIV transmission rates in the US has been demonstrated, and a significant association between the uptake of PrEP and overall declines in HIV diagnoses was identified in a retrospective analysis of data from the National HIV Surveillance System from 2012 to 2016 [9].

Currently, there are two oral PrEP medications approved by the US Food and Drug Administration [10, 11]. Emtricitabine/tenofovir disoproxil fumarate (Truvada $^{\circledR} ; \mathrm{F} / \mathrm{TDF}$ ) $[5-7,12,13]$ was approved in 2012 , and is indicated for PrEP to reduce the risk of sexually acquired HIV-1 in adults at risk [11]. Emtricitabine/tenofovir alafenamide (Descovy ${ }^{\circledR}$; F/TAF) [14] was approved in 2019 for adults and adolescents at risk, excluding individuals at risk from receptive vaginal sex, a population that has not yet been studied with F/TAF [10].

Clinical and real-world studies have demonstrated the efficacy of F/TDF in adults and adolescents at risk of HIV infection; the studies included cisgender men who have sex with men (MSM), people who inject drugs (PWID), transgender women, and heterosexual couples in which one partner was living with HIV $[5-7,12,13,15,16]$. The efficacy and safety of F/TAF PrEP in cisgender men and transgender women who have sex with men ( $\geq 18$ years of age) has been investigated and compared with F/TDF in the Phase 3 DISCOVER study, consisting of a 96-week randomized, double-blind period (which has been completed), and a 48-week open-label extension (which is ongoing) [14]. The results of the DISCOVER study demonstrated that F/TAF was non-inferior to F/TDF for the prevention of HIV at the primary analysis (when $100 \%$ of participants reached 48 weeks of followup and 50\% reached 96 weeks), and also when all participants reached 96 weeks, indicating that the two medications have comparable efficacy at over 99\% [14, 17].

In addition to the proven efficacy of F/TDF and F/TAF, clinical studies have demonstrated well-tolerated safety profiles for the two medications when used as PrEP [12-14]. There are nevertheless important differences between F/TDF and F/TAF in terms of bone and renal safety [14]. The use of F/TDF has been associated with notable decreases in bone mineral density (BMD) and renal function [as measured by estimated glomerular filtration rate (eGFR)] both in individuals with HIV and in individuals who were HIV negative using PrEP [18-20]. F/TAF has been associated with improved maintenance of bone and renal safety parameters versus F/TDF in individuals with HIV [21]. Likewise, this was a key area for investigation in the DISCOVER trial, which compared F/TDF and F/TAF for PrEP. In that study, F/TAF was associated with improved maintenance of BMD and renal function versus decreases in both BMD and eGFR in the F/TDF arm at the end of the 96-week treatment period [14].

The lipid profile and body weight of participants were monitored throughout the DISCOVER trial [17]. In both the F/TDF and F/TAF study arms, decreases were seen from baseline in low-density lipoprotein cholesterol (LDL-C) and total cholesterol (TC) at 96 weeks. Triglyceride levels were increased at 96 weeks in the F/TAF arm, although the increase from baseline, while statistically significant, is unlikely to be clinically meaningful. No significant differences were seen between the study arms in the ratio of TC to high-density lipoprotein cholesterol (HDL-C) or LDL-C:HDL-C, both of which have greater predictive value for cardiovascular disease than the individual parameters in isolation [22]. Among participants receiving F/TDF at baseline, 3\% of those who switched to F/TAF started a lipid-modifying agent versus $0.9 \%$ of those who remained on F/TDF $(p=0.03)$ [23]. Among PrEP-naïve individuals, however, there was no significant difference in the rates of lipid-modifying agent initiation between the arms $(1.3 \%$ vs. $1.0 \%, p=0.27)$ [23].

Weight gain was seen in both the F/TAF and F/TDF groups at week 96 in DISCOVER and was greater in the F/TAF arm (F/TAF: $+1.7 \mathrm{~kg}$; F/TDF: $+0.5 \mathrm{~kg}$ ). The weight gain observed in the F/TAF arm was similar to that seen in longitudinal studies of young adults in the US who were not taking PrEP [24, 25]. 
In this narrative review, we examine the overlap between populations at risk of HIV and those at risk of bone and/or renal conditions, with a particular focus on the US. We also review the clinical dataset for F/TDF and F/TAF to develop an evidence-based algorithm for selecting an appropriate PrEP option for an individual at risk of HIV, based on the biological, behavioral, and health characteristics of the candidate.

This article is based on previously conducted studies and does not contain any studies with human participants or animals performed by any of the authors.

\section{INDIVIDUALS AT RISK OF HIV}

The relative risk of acquiring HIV varies depending on the type of exposure and sexual risk behaviors. At an individual level, the risk of acquiring HIV is multifactorial. However, some factors are considered to increase risk. MSM who have condomless sex or who have had a bacterial sexually transmitted infection, for example, are considered a group at substantial risk of HIV and are recommended to use PrEP by the Centers for Disease Control and Prevention (CDC) [26]. MSM have been shown to have the highest lifetime risk of HIV (around 1 in 6) of all groups in the US (Table 1) [27], and, in 2018 , 70\% of new HIV diagnoses in the US were among MSM [1]. HIV has a disproportionately high impact on racial and ethnic minorities, with Black/African American people, for example, accounting for $42.8 \%$ of HIV diagnoses in the US in 2018, compared with $25.5 \%$ for White people [1]. Black/African American MSM have the highest overall lifetime risk of HIV (around 1 in 2) [27]. Hispanic/Latino MSM have a 1 in 5 lifetime risk, compared with a 1 in 11 lifetime risk among White MSM [27].

Transgender people are particularly at risk of HIV, with estimated prevalence rates in the US of $14.1 \%$ and $3.2 \%$ among transgender women and transgender men, respectively [28]. The lifetime risk of HIV increases with age [27], although the rates of diagnosis are highest in the 25- to 34-year age group [1]. Individuals living in the Southern states in the US have been shown to have the highest lifetime risk of HIV [27], and prevalence is higher among

Table 1 Estimated lifetime risk of HIV by risk group and race/ethnicity [27]

\begin{tabular}{lll}
\hline Risk group & \multicolumn{2}{l}{ Estimated lifetime risk of HIV } \\
\cline { 2 - 3 } & Male & Female \\
\hline Total & 1 in 68 & 1 in 253 \\
Risk group & & NA \\
MSM & 1 in 6 & 1 in 266 \\
Heterosexual & 1 in 524 & 1 in 26 \\
PWID & 1 in 42 & \\
Race/ethnicity & & 1 in 403 \\
American Indian/Alaska Native & 1 in 131 & 1 in 943 \\
Asian & 1 in 176 & 1 in 54 \\
Black/African American & 1 in 22 & 1 in 256 \\
Hispanic/Latinx & 1 in 51 & 1 in 432 \\
Native Hawaiian/other Pacific Islander & 1 in 95 & 1 in 941 \\
White & 1 in 140 &
\end{tabular}

$M S M$ men who have sex with men, $N A$ not applicable, $P W I D$ people who inject drugs 
individuals who have a lower socioeconomic status [29]. Finally, PWID have an increased lifetime risk of HIV, which is higher in females than males (1:26 vs. 1:42, respectively) [27].

\section{INDIVIDUALS AT RISK OF HIV AND RENAL CONDITIONS}

\section{Renal Disease in the US}

Approximately 15\% (37 million) of people in the US are estimated to have chronic kidney disease (defined as an eGFR $<60 \mathrm{ml} / \mathrm{min}$ / $1.73 \mathrm{~m}^{2}$ for $\geq 3$ months) [30, 31]. Furthermore, diabetes and hypertension are common, with prevalence rates in the US of $\sim 13 \%$ and $\sim 46 \%$, respectively [32, 33]. Rates of kidney disease, diabetes, and hypertension are generally more common in males versus females, and the risk increases with age [32-34].

\section{Risk Factors}

\section{Race/Ethnicity}

Black/African American and Hispanic/Latinx individuals (particularly MSM) are disproportionately affected by HIV [27], and also have a high prevalence of conditions such as hypertension, diabetes, and obesity [34, 35], which may be associated with the elevated prevalence of kidney failure and end-stage renal disease [33-36].

\section{Age}

Aging is associated with changes to the renal system, gradually leading to declines in renal function and overall renal health [37]. While chronic kidney disease is more prevalent in the elderly, physiological declines in kidney function can begin as early as 30-40 years of age depending on many factors, some of which are listed below [37, 38].

\section{Alcohol/Substance Use Disorder}

Individuals with alcohol and/or substance use disorders (e.g., methamphetamines) are more likely to engage in sexual behaviors that place them at risk of HIV $[39,40]$. Studies have found that people who identified as gay or bisexual have a high likelihood of lifetime substance use disorders [41, 42]. Methamphetamines, cocaine, opioids, marijuana, and alcohol have all been shown to have a negative effect on renal health [43]. These risk factors should be discussed with individuals and taken into consideration when individualizing PrEP medication selection.

\section{Tobacco Use}

Gay, bisexual, and transgender populations have been reported to have high tobacco use rates [33]. Tobacco use has numerous negative effects that may cause tubular dysfunction and glomerulosclerosis, leading to the progression of chronic kidney disease [44]. Notably, the use of e-cigarettes has increased in recent years, particularly among younger populations [45], which may also reduce renal function as has been shown in mice exposed to e-cigarette vapor [46].

\section{Concomitant Medications}

Many medications can contribute to declines in renal function, which include several first-line agents for the treatment of mental health conditions [47]. Notably, some mental health conditions can be associated with a higher likelihood of acquiring HIV, as they may be linked to high-risk sexual behavior, alcohol use before sex, or reduced adherence to PrEP [48].

A variety of other medications may also affect renal health. Angiotensin-converting enzyme inhibitors/angiotensin receptor blockers $[49,50]$, antibiotics (methicillins/penicillins, cephalosporins, aminoglycosides) [49], and chemotherapies (cisplatin, ifosfamide, gemcitabine, mitomycin) [51] are just a few examples; the list of drugs with potential nephrotoxicity is extensive $[52,53]$. As a result, an individual's medical history, including the use of concomitant medications that may affect renal health, should be considered before selecting the appropriate PrEP medication. 


\section{Diet}

Data suggest that MSM have significantly higher estimated rates of eating disorders than heterosexual men [54]. Eating disorders, such as anorexia or bulimia nervosa, can contribute to the development of kidney disease [55]. Careful assessment of diet and symptoms of eating disorders should be considered in MSM.

\section{Renal Disease Rates in PrEP Users: Clinical Studies and Real-World Studies}

Evidence suggests that a substantial proportion of individuals who were eligible for PrEP in clinical studies had mildly reduced renal function at baseline. A large implementation cohort study in Australia included individuals with an eGFR of $\geq 60 \mathrm{ml} / \mathrm{min} / 1.73 \mathrm{~m}^{2}$ and found that $28.5 \%$ had mildly reduced renal function at baseline (eGFR $\geq 60$ to $<90 \mathrm{ml} / \mathrm{min} / 1.73 \mathrm{~m}^{2}$ ), and that these individuals had an increased risk of further renal impairment (eGFR $<60 \mathrm{ml}$ / $\min / 1.73 \mathrm{~m}^{2}$ ) [56]. Similarly, a prospective cohort study of PrEP in the US identified that $16.6 \%$ of MSM and transgender women in the study had mildly reduced kidney function at baseline $\left(e G F R \geq 60\right.$ to $<90 \mathrm{ml} / \mathrm{min} / 1.73 \mathrm{~m}^{2}$ ) [57].

A variety of other conditions that may affect renal health can be found in some individuals at risk of HIV using PrEP medication, with the CDC recommending frequent renal monitoring (at least every 6 months or more frequently if risk factors are present) for F/TDF users [26]. Table 2 summarizes the prevalence of mildly reduced renal function and conditions affecting renal health at baseline among PrEP users in clinical studies [56-59]. Collectively, these data challenge the perception that PrEP users only consist of healthy individuals without pre-existing renal impairment or conditions that impact renal health.

Table 2 Prevalence of mildly reduced renal function and conditions affecting renal health at baseline in clinical studies of PrEP

\begin{tabular}{|c|c|c|c|c|c|c|}
\hline \multirow[t]{2}{*}{ Population } & \multirow{2}{*}{$\begin{array}{l}\text { Sample } \\
\text { size, } n\end{array}$} & \multicolumn{4}{|l|}{ Baseline prevalence, \% } & \multirow[t]{2}{*}{ References } \\
\hline & & $\begin{array}{l}\text { Suboptimal eGFR } \\
\text { levels }(\geq 60-<90 \mathrm{ml} / \\
\left.\min / 1.73 \mathrm{~m}^{2}\right)\end{array}$ & Hyperlipidemia & Hypertension & $\overline{\text { Diabetes }}$ & \\
\hline $\begin{array}{l}\text { MSM and transgender } \\
\text { women in a } \\
\text { multinational study }\end{array}$ & 5387 & NA & 12 & $10-11$ & 3 & {$[58]$} \\
\hline $\begin{array}{l}\text { MSM and transgender } \\
\text { women in the US }\end{array}$ & 557 & 16.6 & NA & 11.3 & 1.6 & {$[57]$} \\
\hline $\begin{array}{l}\text { MSM and transgender } \\
\text { women in a } \\
\text { multinational study }\end{array}$ & 1224 & NA & NA & 2 & NA & [59] \\
\hline $\begin{array}{c}\text { Individuals at high risk } \\
\text { of HIV in Australia }\end{array}$ & 5868 & 28.5 & NA & NA & NA & {$[56]$} \\
\hline
\end{tabular}

eGFR estimated glomerular filtration rate, $M S M$ men who have sex with men, $N A$ not applicable, $\operatorname{PrEP}$ pre-exposure prophylaxis

a Includes US, Canada, UK, Italy, Spain, Netherlands, Germany, France, Austria, Ireland, and Denmark

b Includes US, Thailand, South Africa, Brazil, Ecuador, and Peru 


\section{INDIVIDUALS AT RISK OF HIV AND BONE CONDITIONS}

\section{Osteoporosis and Low Bone Mass in the US}

In the US, a society with an aging population, a large proportion of individuals $\geq 50$ years of age have osteoporosis or low bone mass, which is estimated to reach 64 million by 2020 [60]. Young adults and adolescents are highly sensitive to changes in bone health before they achieve peak bone mass [61]. If bone health is disturbed during this time and peak bone mass is diminished, younger individuals might be at increased risk of osteoporosis later in life [62].

\section{Risk Factors}

\section{Race/Ethnicity}

As noted earlier, Hispanic/Latinx individuals are at a high lifetime risk of HIV. In one study, Mexican Americans also had the highest prevalence of osteoporosis (13.4\%) compared with groups defined as 'non-Hispanic White' (10.2\%) and 'non-Hispanic Black' (4.9\%) [60].

\section{Age}

Osteoporosis and bone loss are generally associated with aging, with rates being higher in older populations [60]. However, bone health is also an important consideration in younger individuals, as bones grow rapidly during adolescence until they reach peak mass, typically by 30 years of age [61, 63]. Lifestyle factors and medication choices that affect bone growth during these years and result in an inadequate peak bone mass may lead to low bone density and skeletal fragility later in life [62]. Efforts should therefore be made to avoid disrupting osteogenesis if at all possible.

\section{Diet and Physical Activity}

Dietary deficiencies in calcium; vitamins D, C, and $\mathrm{K}$; manganese; potassium; and zinc can contribute to poor bone health, as can low physical activity [64]. Lactose intolerance is associated with reduced bone density, which may be related to avoidance of dairy foods that are high in calcium [65]. Notably, lactose intolerance rates are higher in Black/African Americans (who are disproportionately affected by HIV) than Whites [66]. Individuals living in poverty or underserved neighborhoods are more likely to have less access to nutritional foods and have lower physical activity [67]. Discussions between healthcare professionals and candidates for PrEP are therefore warranted to ascertain information on lifestyle factors, such as diet and physical activity, which could help in the personalization of PrEP medication.

Eating disorders may also contribute to dietary deficiencies. Individuals with anorexia or bulimia often have reduced BMD and increased risk of bone conditions such as osteoporosis and osteopenia [68, 69].

\section{Alcohol/Substance Use Disorder}

As noted previously, individuals with alcohol use disorder or who use methamphetamines are more likely to engage in behaviors that place them at risk of HIV. Excessive alcohol intake has been associated with a significant increase in osteoporotic and hip fracture risk [70]. Similarly, the use of methamphetamines has been associated with a decrease in BMD [71]. Notably, a small clinical study in the Republic of Korea found that $22 \%$ and $76 \%$ of hospitalized methamphetamine users had osteoporosis and osteopenia, respectively, indicating a high incidence in this population [71].

\section{Tobacco Use}

Smoking tobacco has been shown to lower BMD and increase the risk of osteoporosis and fracture [72]. Tobacco use may therefore have a negative impact on bone health in individuals at risk of HIV, particularly in gay, bisexual, and transgender populations in which smoking rates are high [33]. As noted earlier, the use of e-cigarettes is on the rise in younger populations, who are also sensitive to factors that affect peak bone mass. 


\section{Other Concomitant Medications}

Concomitant medications, particularly the use of corticosteroids, are a key consideration for bone health in individuals at risk of HIV. Shortand long-term use of corticosteroids has been associated with bone loss, while long-term use may increase fracture risk [73-75]. A wide variety of other medications can affect bone health, including antidepressants, medications for diabetes, and proton pump inhibitors [76]. Consequently, careful assessment of concomitant medications that may affect bone health should be performed to help guide the appropriate choice of PrEP medication.

\section{Evidence of Osteoporosis, Osteopenia, and Low BMD Among PrEP Users in Clinical Studies}

As described above, there is potential for considerable overlap between individuals at risk of HIV and those who may have (or be at risk of) conditions impacting bone health. When we examine PrEP studies, we see that this has actually translated into a substantial proportion of the study populations reporting BMD-related conditions at baseline (Table 3) [77-81]. Most significantly, in the largest clinical PrEP study to date, the DISCOVER study found that $\sim 24-29 \%$ of all individuals in the BMD

Table 3 Prevalence of osteoporosis or osteopenia and low BMD at baseline in clinical studies of PrEP

\begin{tabular}{|c|c|c|c|c|}
\hline Population & $\begin{array}{l}\text { Sample size, } \\
n\end{array}$ & Region & $\begin{array}{l}\text { Prevalence, } \\
\%\end{array}$ & References \\
\hline \multicolumn{5}{|l|}{ Osteoporosis or osteopenia } \\
\hline \multirow[t]{2}{*}{ MSM and transgender women in a multinational study ${ }^{a}$} & $375^{\mathrm{b}}$ & Spine & $27-29$ & {$[77]$} \\
\hline & & Hip & $24-25$ & \\
\hline \multicolumn{5}{|l|}{ Low $\mathrm{BMD}^{\mathrm{c}}$} \\
\hline \multirow[t]{4}{*}{ MSM in the US } & 210 & Spine & 8.1 & {$[78]$} \\
\hline & & Hip & 2.4 & \\
\hline & & Femoral neck & 0.5 & \\
\hline & & $\geq 1$ of the above & 9.5 & \\
\hline \multirow[t]{2}{*}{ MSM and transgender women in a multinational study ${ }^{\mathrm{d}}$} & 498 & Spine & 12 & {$[79]$} \\
\hline & & Hip & 2 & \\
\hline \multirow[t]{3}{*}{ Heterosexual men and women in Botswana } & 220 & Spine & 3.6 & {$[80]$} \\
\hline & & Arm & 4.5 & \\
\hline & & $\geq 1$ of the above & $6.8^{\mathrm{e}}$ & \\
\hline \multirow[t]{2}{*}{ Heterosexual women in Uganda and Zimbabwe } & 518 & Spine & 5.8 & {$[81]$} \\
\hline & & Hip & 0.6 & \\
\hline
\end{tabular}

$B M D$ bone mineral density, $M S M$ men who have sex with men, $\operatorname{PrEP}$ pre-exposure prophylaxis

${ }^{a}$ Includes US, Canada, UK, Italy, Spain, Netherlands, Germany, France, Austria, Ireland, and Denmark

b BMD substudy included 375 participants out of the total number of 5387

c Defined as a Z-score below - 2.0

d Includes US, Thailand, South Africa, Brazil, and Peru

${ }^{\mathrm{e}}$ Men, $11.3 \%$; women, $2.6 \%$ 
subanalysis had either osteopenia or osteoporosis in the spine and/or hip at baseline [77].

\section{CHOOSING A PrEP MEDICATION}

At PrEP initiation, an accurate assessment of the HIV risk of an individual should be performed. HIV risk-prediction models, such as SexPro for MSM in the US (developed to be inclusive of Black MSM), may help assess risk and target PrEP [82]. Key groups that are recommended for PrEP (if they are at risk of HIV acquisition) include sexually active MSM, transgender women, and PWID [26]. Collectively, evidence suggests that there is a substantial population of individuals at risk of HIV who also either have, or are at risk of developing, bone or renal impairments. This population may particularly benefit from taking F/TAF versus F/TDF for PrEP, due to its improved bone- and renal-related safety profile [17]. Notably, when considering PrEP, a careful evaluation of all concomitant illnesses and medications should be performed before initiation. Herein, we present an algorithm outlining the key steps in the decision to prescribe either $\mathrm{F} / \mathrm{TAF}$ or $\mathrm{F} / \mathrm{TDF}$ in individuals who have, or are at risk of developing, bone or renal impairments (see Fig. 1).

\section{Consideration \#1}

An assessment of the type of sexual activity that the PrEP candidate participates in is an important first step. If the PrEP candidate is at risk of HIV through receptive vaginal sex (e.g., a cisgender woman), then F/TDF should be prescribed as it is the only PrEP medication currently approved for this population $[10,11]$.

\section{Supporting Evidence}

The approval of F/TDF for use by individuals at risk from receptive vaginal sex has been based on randomized clinical trial data from the Partners PrEP study, which demonstrated its efficacy and safety [15]. In this study, HIV incidence rates were 0.5 and 1.99 per 100 person-years in the F/TDF and placebo groups, respectively, which translated to a $75 \%$ risk reduction with F/TDF versus placebo. Additionally, the incidence of serious adverse events (AEs) were similar between the two treatment groups. F/TAF has not yet been investigated in individuals at risk of HIV from receptive vaginal sex [10].

\section{Consideration \#2}

On-demand PrEP dosing (two tablets 2-24 h before sex, one tablet $24 \mathrm{~h}$ later, and another tablet $24 \mathrm{~h}$ after that) may be considered in a subset of MSM. Although no PrEP medication is currently approved for on-demand dosing, the use of on-demand F/TDF has been shown to be highly effective at preventing HIV in some MSM [83-85]; however, these studies were conducted in a principally White population. High levels of once-daily F/TDF PrEP initiation have been demonstrated among at-risk Black MSM [86], but no studies have examined on-demand dosing in principally Black MSM populations to date. As such, the World Health Organization recommends that F/TDF could be considered in a limited population of MSM who have infrequent sex, are able to plan for sex at least $2 \mathrm{~h}$ in advance, and do not have chronic hepatitis $B$ infection [87]. In this subset of MSM, on-demand F/TDF could be an option depending on the preferences of the individual; F/TAF has not yet been investigated for on-demand PrEP.

\section{Supporting Evidence}

Most studies of PrEP to date have been of daily dosing; however, a randomized clinical study investigating on-demand PrEP for MSM at high risk of HIV infection demonstrated a statistically significant $86 \%$ reduction in infection risk with F/TDF versus placebo [84]; the study population was mostly White. An open-label extension of this study demonstrated long-term effectiveness (median follow-up 18.4 months) of on-demand F/TDF in this population [83]. Finally, a post-hoc subanalysis from this study in individuals having infrequent sex (median of five times per month) demonstrated a 100\% reduction in HIV infection risk with F/TDF versus placebo [85]. 


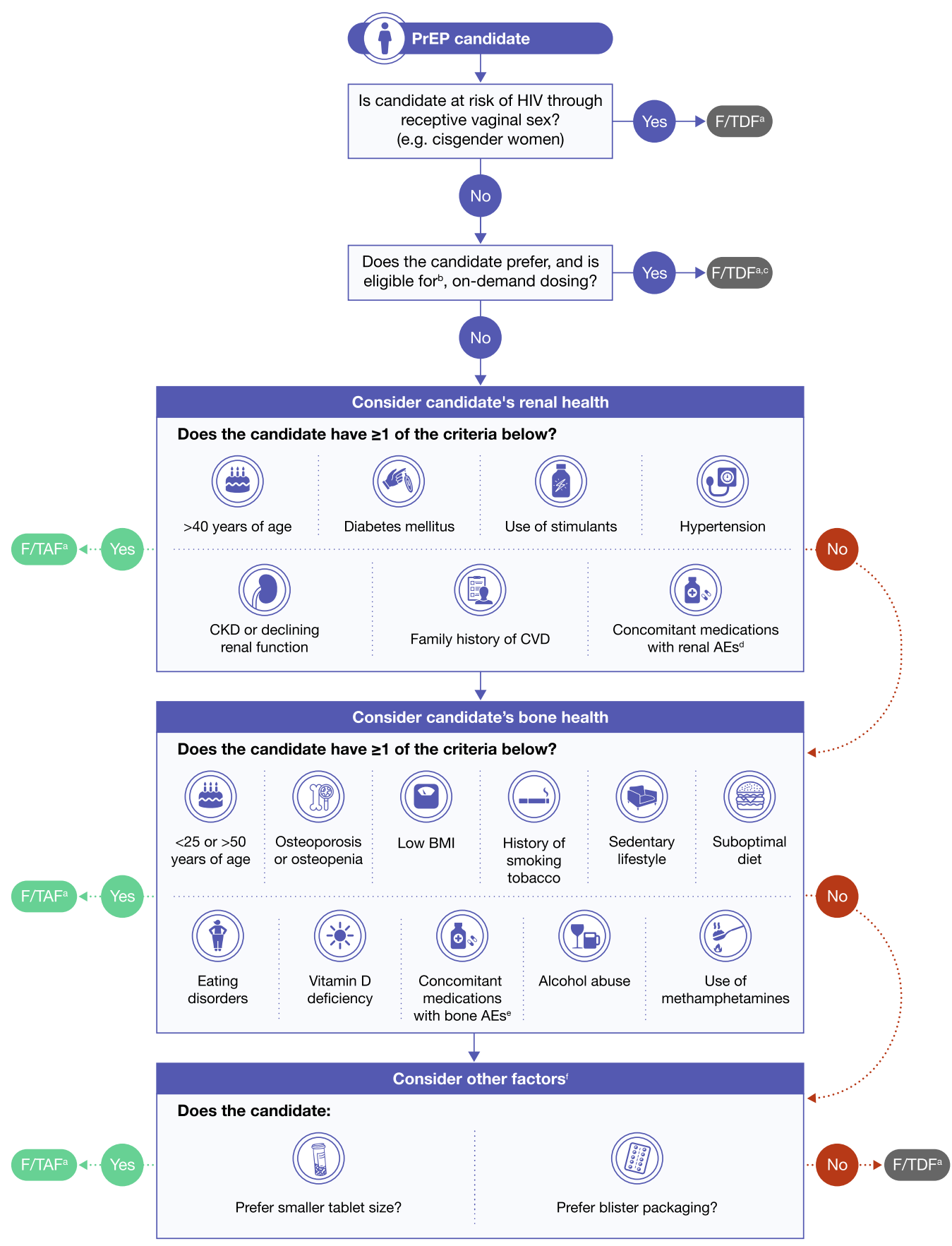

Fig. 1 Algorithm for choosing PrEP. $A C E i$ angiotensinconverting enzyme inhibitor, $A E$ adverse event, $A R B$ angiotensin receptor blocker, $B M I$ body mass index, $C K D$ chronic kidney disease, $C V D$ cardiovascular disease, F/TAF emtricitabine/tenofovir alafenamide, $F / T D F$ emtricitabine/tenofovir disoproxil fumarate, MSM men who have sex with men, NSAID non-steroidal anti-inflammatory drug, $\operatorname{PrEP}$ pre-exposure prophylaxis. ${ }^{\text {aIf no significant }}$ drug-drug interactions. ${ }^{b}$ Eligibility is limited to MSM who have infrequent sex, are able to plan for sex at least $2 \mathrm{~h}$ in advance, and do not have chronic hepatitis $\mathrm{B}$ infection. ${ }^{c} \mathrm{~F} / \mathrm{TDF}$ is currently not approved for on-demand dosing. ${ }^{\mathrm{d}}$ Including psychotropic medications, NSAIDs, ACEi/ ARBs, certain antibiotics, certain chemotherapies. ${ }^{\mathrm{e}}$ Including corticosteroids. ${ }^{f}$ Weight gain has been observed among individuals using both F/TAF and F/TDF, with slightly less weight gain among those on F/TDF, which may be a factor to consider when discussing PrEP options 
Table 4 Established and potentially significant drug interactions with F/TDF and F/TAF $[10,11]$

\begin{tabular}{lll}
\hline $\begin{array}{l}\text { Concomitant drug } \\
\text { class }{ }^{\mathrm{a}}: \text { drug name }\end{array}$ & $\begin{array}{l}\text { Effect on drug } \\
\text { concentration }\end{array}$ & Clinical comments \\
\hline
\end{tabular}

F/TDF

Nucleoside reverse transcriptase inhibitors

$\begin{array}{ccc}\text { Increased } & \text { Monitor patients closely for adverse reactions } \\ \text { didanosine } & \end{array}$

HIV-1 protease inhibitors

$\begin{array}{ll}\text { Atazanavir } & \begin{array}{c}\text { Decreased } \\ \text { atazanavir }\end{array} \\ \text { Lopinavir/ritonavir } & \text { Increased TDF } \\ \text { Atazanavir/ritonavir } & \text { Increased TDF } \\ \text { Darunavir/ritonavir } & \text { Increased TDF }\end{array}$

Hepatitis $\mathrm{C}$ antiviral agents

Ledipasvir/sofosbuvir Increased TDF

Atazanavir $300 \mathrm{mg}$ should be given with ritonavir $100 \mathrm{mg}$

Monitor patients closely for adverse reactions

Monitor patients closely for adverse reactions. In patients receiving F/TDF concomitantly with ledipasvir/sofosbuvir and an HIV-1 protease inhibitor/ritonavir or an HIV-1 protease inhibitor/cobicistat combination, consider an alternative $\mathrm{HCV}$ or antiretroviral therapy

F/TAF

HIV-1 protease inhibitors

Tipranavir/ritonavir $\quad$ Decreased TAF

Coadministration not recommended

Anticonvulsants

Carbamazepine

Decreased TAF

Consider alternative anticonvulsants

Oxcarbazepine

Decreased TAF

Phenobarbital

Decreased TAF

Phenytoin

Decreased TAF

Antimycobacterials

\begin{tabular}{|c|c|c|}
\hline Rifabutin & Decreased TAF & Coadministration with rifabutin, rifampin, or rifapentine not \\
\hline Rifampin & Decreased TAF & recommended \\
\hline Rifapentine & Decreased TAF & \\
\hline
\end{tabular}


Table 4 continued

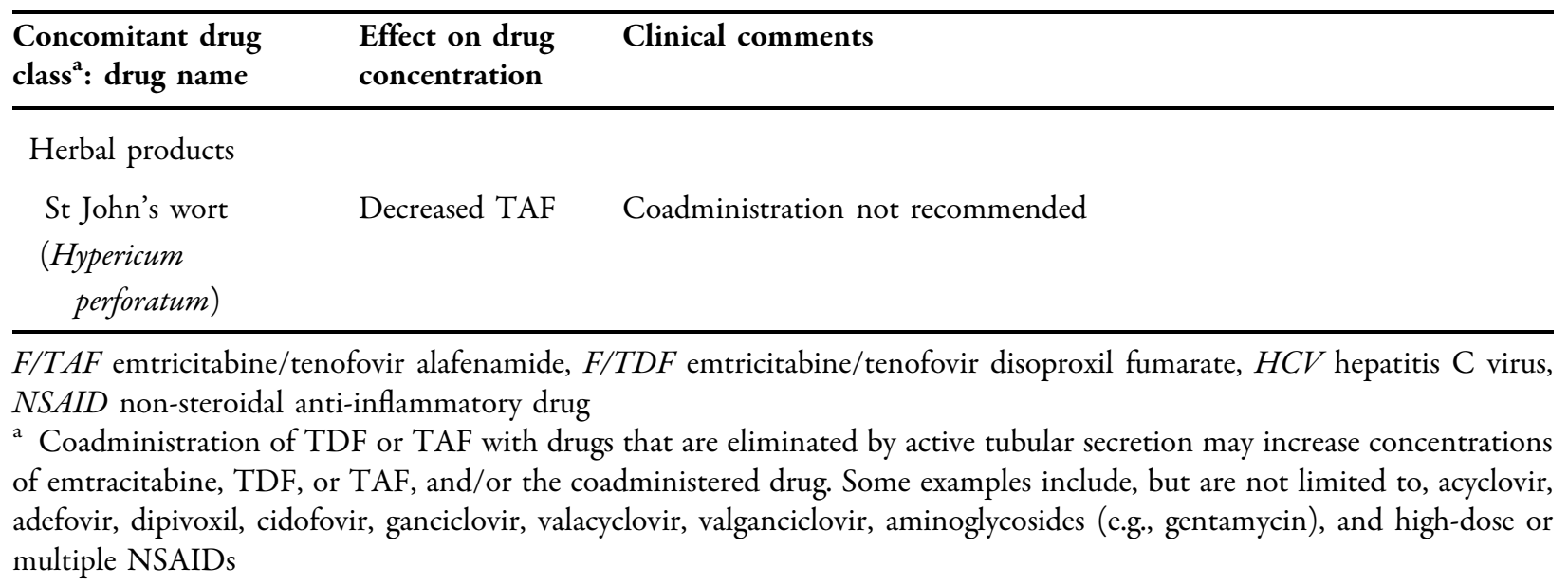

\section{Consideration \#3}

F/TDF and F/TAF have different drug-drug interaction considerations noted in their prescribing information that could impact the choice of PrEP medication (Table 4) [10, 11]. For example, people receiving F/TDF and some hepatitis $\mathrm{C}$ antiviral agents (sofosbuvir/velpatasvir, sofosbuvir/velpatasvir/voxilaprevir, or ledipasvir/sofosbuvir) should be monitored for AEs associated with TDF [11]. In contrast, the use of F/TAF should be avoided in combination with some anticonvulsants (some of which may be being used as mood stabilizers) (carbamazepine, oxcarbazepine, phenobarbital, phenytoin), antimycobacterials (rifabutin, rifampin, rifapentine), and St John's wort [10].

\section{Consideration \#4}

If the PrEP candidate is at risk of sexually acquired HIV and is an appropriate candidate for F/TAF, then renal health should be considered next. Key criteria for renal health considerations include being $>40$ years of age, evidence of chronic kidney disease or declining renal function, use of concomitant medications with known renal AEs, a history of having a condition that may impact renal health (e.g., diabetes, hypertension, or a family history of cardiovascular disease), or use of stimulants. F/TAF should be considered in any PrEP candidate with one or more of the above key criteria.

\section{Supporting Evidence}

Clinical studies have identified differences in the effects of F/TAF and F/TDF on kidneys, based on renal biomarkers. There is a well-documented association between F/TDF and modest declines in measures of renal function, such as estimated creatinine clearance $(\mathrm{eCrCl})$ and eGFR, when used for HIV treatment and prevention $[18,19,88-90]$. Given the known effects of F/TDF on renal function, the CDC has recommended that serum creatinine $(\mathrm{Cr})$ is measured at baseline, and any individual with an eCrCl of $<60 \mathrm{ml} / \mathrm{min}$ should not be prescribed F/TDF [26]. Renal health must be evaluated either before or when prescribing PrEP medications, to avoid administration to individuals with renal impairment or those at risk of declining renal function $[56,57,59]$.

The available evidence indicates that F/TAF is not associated with a significant decline in renal function when used for PrEP [14]. F/TAF can be prescribed to individuals with lower renal function in comparison with F/TDF, and is recommended in individuals with an $\mathrm{eCrCl} \geq 30 \mathrm{ml} / \mathrm{min}$ or with an $\mathrm{eCrCl}<15 \mathrm{ml} /$ min and who are on chronic hemodialysis [10]. The DISCOVER study demonstrated that significant eGFR changes were not identified in the F/TAF arm, with significant eGFR decreases $(-4.1 \mathrm{ml} / \mathrm{min})$ observed in the $\mathrm{F} / \mathrm{TDF}$ group at 96 weeks $(p<0.001)$ [17]. Importantly, these differences in eGFR between F/TAF and F/TDF were evident at 96 weeks among older individuals ( $\geq 50$ years of age) $(p<0.001)$ (Fig. 2) [17], 
who have been shown to have a higher risk of developing renal dysfunction when taking F/TDF [56]. Two biomarkers have been shown to be associated with proximal renal tubule dysfunction when elevated: retinol binding protein (RBP) to Cr ratio and $\beta 2$ microglobulin $(\beta 2 \mathrm{M})$ to Cr ratio $[91,92]$. In the DISCOVER study, there were no significant changes in urine RBP:Cr and $\beta 2 \mathrm{M}$ :Cr from baseline in the F/TAF group, while levels were significantly higher in the F/TDF group at 96 weeks $(p<0.001)$, which was again evident in individuals $\geq 50$ years of age $(p<0.001)$ (Fig. 2) [17].

The DISCOVER study also found a numerically lower number of study drug-related renal AEs in the F/TAF and F/TDF groups (14/2694 vs. 26/2693, respectively) [14]. Similarly, renal AEs leading to discontinuation were $2 / 2694$ and $6 / 2693$ in the F/TAF versus F/TDF groups, respectively [14]. The overall number of AEs leading to discontinuation was low in both groups at 96 weeks [14]. Notably, F/TAF showed a lack of impact on glucose levels and fasting lipids at 96 weeks, suggesting little effect on metabolic health [17].

The efficacy of F/TAF and F/TDF in transgender women from DISCOVER, which included those taking gender-affirming hormones, was evaluated at the primary analysis. Although sample sizes were small, no HIV infections were found for any transgender women using F/TAF or F/TDF [93]. Importantly, the incidence of AEs and renal safety outcomes in the two treatment groups were similar [93]. Additionally, intracellular drug levels of tenofovir diphosphate were higher in transwomen who had received F/TAF versus those receiving F/TDF [93].

\section{Consideration \#5}

Bone health should also be considered. Key criteria include the following: $<25$ or $>50$ years of age, occurrence of bone-related conditions such osteoporosis or osteopenia, previous or current corticosteroid use, lifestyle factors that have a negative impact on bone health (e.g., history of tobacco smoking, sedentary lifestyle, poor diet, alcohol use disorder, use of methamphetamines), eating disorders, vitamin $\mathrm{D}$ deficiency, or low body mass index. F/TAF should be considered in any PrEP candidate meeting one or more of these criteria.

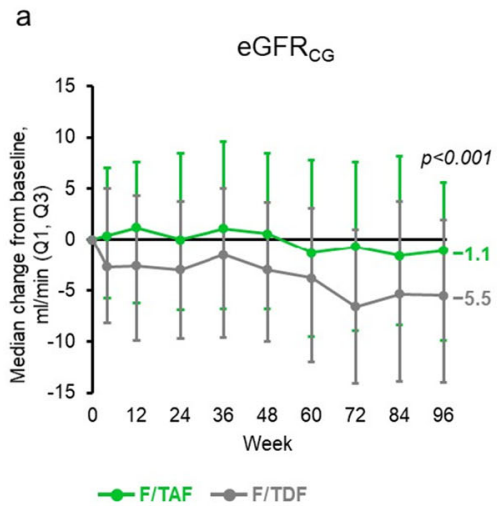

Fig. 2 Markers of renal function in individuals $\geq 50$ years of age using F/TAF or F/TDF for PrEP (DISCOVER study) (reproduced with permission from [17]). $\mathrm{Cr}$ creatinine, $e G F R_{C G}$ estimated glomerular filtration rate (based on the Cockcroft-Gault equation), $F / T A F$ emtricitabine/tenofovir alafenamide, $F / T D F$ emtricitabine/tenofovir disoproxil fumarate, $\operatorname{PrEP}$ pre-exposure prophylaxis,
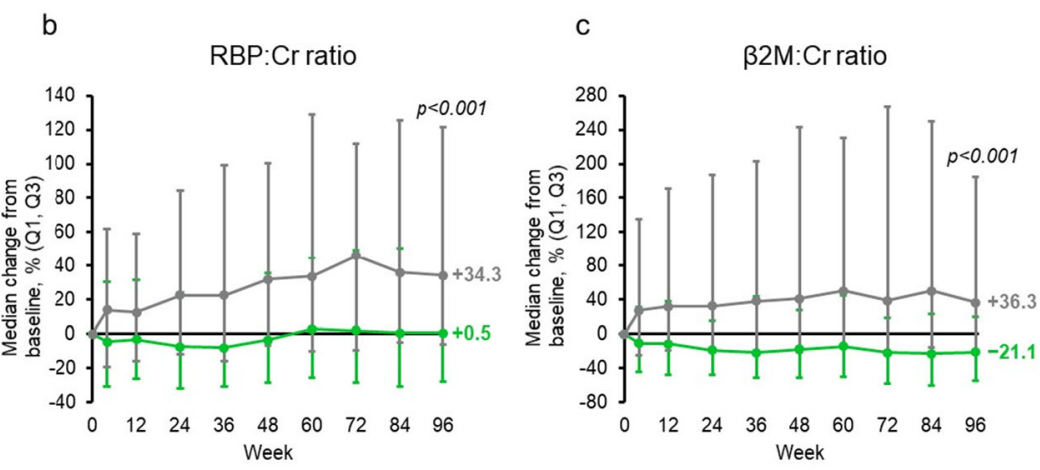

$R B P$ retinol binding protein, $\beta 2 M \beta 2$ microglobulin. Median changes from baseline in (a) eGFR $\mathrm{CG}_{\mathrm{C}}$ and (b), (c) proximal tubular protein to $\mathrm{Cr}$ ratios: (b) $\mathrm{RBP}: \mathrm{Cr}$ ratio and (c) $\beta 2 \mathrm{M}: \mathrm{Cr}$ ratio. $p$ values at 96 weeks are derived from the Van Elteren test stratified by baseline F/TDF for PrEP to compare the two study arms 


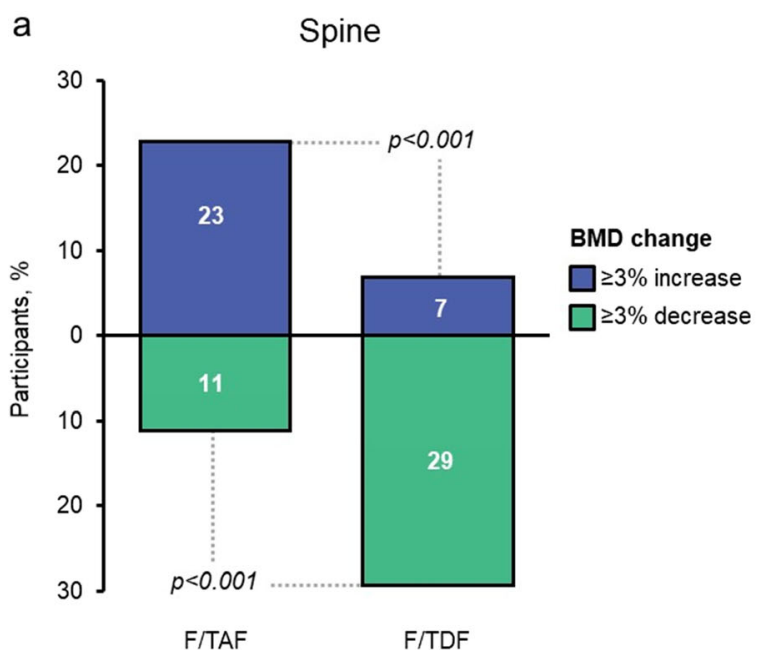

Fig. $3 \mathrm{BMD}$ at 96 weeks in individuals using F/TAF or F/TDF for PrEP (DISCOVER study) (reproduced with permission from [17]). BMD bone mineral density, $F / T A F$ emtricitabine/tenofovir alafenamide, $F / T D F$ emtricitabine/tenofovir disoproxil fumarate, $\operatorname{PrEP}$ pre-exposure prophylaxis. Proportion of participants with $\geq 3 \%$ change

\section{Supporting Evidence}

F/TDF may be associated with declines in BMD when used for PrEP or HIV treatment, in comparison with F/TAF, which showed no effect on BMD [20]. A systematic review and meta-analysis included a mixed group of studies wherein F/TDF was used as PrEP, HIV treatment, and hepatitis B virus treatment [20]. When taken as PrEP, F/TDF was associated with a minor BMD decrease in the lumbar spine and total hip (mean differences of $-0.82 \%$ and $-0.81 \%$, respectively), although a larger decrease in BMD was seen in the HIV treatment studies [20]. Importantly, two open-label studies from the Adolescent Trials Network of PrEP evaluated BMD changes in young adult/adolescent MSM $[16,94]$. One study in individuals $18-22$ years of age identified modest but significant decreases in BMD in the hip and whole body (median differences of $-0.44 \%$ and $-0.61 \%$, respectively) with F/TDF at week 24 [94]. The other study included individuals 15-17 years of age and found a significant decrease in the total body BMD Z-score at week 48 [16]. A subsequent extension study showed that BMD Z-scores in the spine and whole body remained below

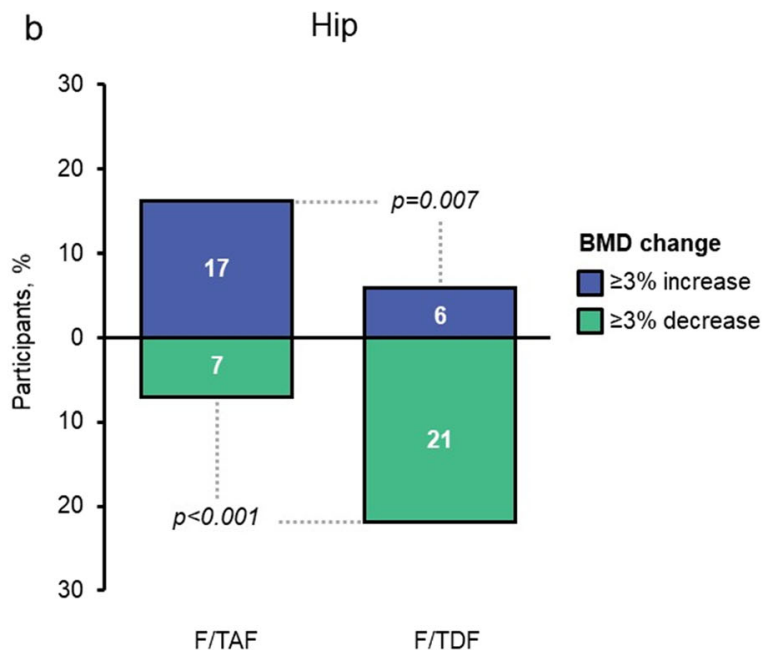

in BMD from baseline in (a) spine and (b) hip. All $p$ values are based on dichotomized response from Cochran-Mantel-Haenszel test for nominal data (general association statistic), adjusting for baseline F/TDF for PrEP

baseline in individuals 15-19 years of age 48 weeks following discontinuation of PrEP [95]. Despite the potential effects of F/TDF on bone health, the CDC does not currently recommend BMD assessment before initiation of F/TDF, although individuals with a history of fractures, or at significant risk of osteoporosis, are recommended to be referred for appropriate consultation and management [26]. Although not specifically recommended by the CDC, BMD measurement may provide additional clinically important information to guide decision making before initiating F/TDF for PrEP and could be considered by clinicians.

Unlike F/TDF, F/TAF has not been associated with a decline in BMD when used for PrEP [14]. In a prespecified subgroup analysis, the DISCOVER study demonstrated BMD increases among individuals in the F/TAF group, with levels significantly higher than F/TDF in the spine and hip at 48 and 96 weeks (Fig. 3) $[14,17]$. Similar effects on BMD were seen between individuals $<25$ and $\geq 25$ years of age at both time points $[14,17]$. F/TAF was associated with a significantly lower rate of osteoporosis and osteopenia in the spine than F/TDF 
after 48 weeks of medication, with low and similar fracture rates (2\%) in both PrEP groups [96].

\section{Consideration \#6}

Finally, F/TAF should be considered in candidates who prefer a smaller tablet size or blister packaging.

\section{Supporting Evidence}

Candidate preferences about tablet size are a key consideration as F/TAF is about one-third of the size of F/TDF (249 vs. $767 \mathrm{~mm}^{3}$, respectively). In general, larger tablets are harder to swallow, which may act as a barrier to medication adherence and reduce long-term adherence $[97,98]$. A study conducted in the US identified that many individuals reported or anticipated difficulty in taking PrEP tablets (F/TDF), with aversion to size being a common theme [99]. Additionally, almost all individuals stated that reducing the size of the PrEP tablet would increase their willingness to take medication [99]. Collectively, these data indicate that F/TAF may be a preferred option for individuals at risk of HIV, especially those who prefer a smaller tablet or who struggle to swallow a larger tablet.

F/TDF is supplied in a bottle, whereas F/TAF is also available in a DayTracker ${ }^{\mathrm{TM}}$ perforated blister pack [100, 101]. Blister packaging may increase medication adherence and avoid errors, by helping the individual self-monitor medication consumption [102]. Some individuals may find separate blister packs less conspicuous, which can be important given the high level of stigma that remains around HIV and PrEP use. Given the importance of daily PrEP adherence for optimal effectiveness in preventing HIV, the candidate's preferences should be considered, and the DayTracker ${ }^{\mathrm{TM}}$ blister pack for F/TAF could be particularly useful for individuals who are at risk of forgetting to take their medication. Improving adherence to PrEP is essential for ensuring that real-world effectiveness matches the efficacy levels achieved in clinical trials. Any factors that reduce an individual's willingness or ability to use PrEP correctly—such as large tablet size or inconvenient packaging-risk compromising clinical outcomes.

\section{NOVEL MEDICATIONS FOR PrEP IN DEVELOPMENT}

A number of alternative strategies for PrEP are in development, including the use of implants or long-acting injections to achieve sustained dosing. A recent double-blind, placebo-controlled Phase 1 trial found that implant-based release of the investigational nucleoside reverse transcriptase translocation inhibitor, MK-8591 (islatravir), for example, was generally well tolerated [103]. Moreover, an interim analysis of data from the HIV Prevention Trials Network 083 study reported that the investigational drug cabotegravir was superior to F/TDF in MSM and transgender women in preventing HIV acquisition when injected once every 8 weeks [104]. Additionally, the HIV Prevention Trials Network (HPTN) 084 study recently reported on the HPTN website that a regimen containing cabotegravir injected once every 8 weeks was superior to daily oral F/TDF at preventing HIV acquisition in cisgender women-we await to see these results published in a peer-reviewed journal [105]. These long-acting agents have the potential to further revolutionize the choice of PrEP for individuals at risk.

Another approach under development is the use of broadly neutralizing antibodies (bnAbs). These have been shown to reduce the risk of simian HIV infection in non-human primates [106]. While no single bnAb would be able to neutralize all strains of HIV in humans, cocktails of multiple bnAbs could provide effective protection [107]. Two large Phase $2 b$ trials of VRC01, a bnAb that targets the conserved CD4 binding site of the HIV envelope, are currently under way in humans. Modeling suggests that the overall prevention efficacy of VRC01 may be between 37 and $82 \%$ [108], suggesting that the antibody therapy, while valuable, will not be an immediate substitute for pharmaceutical approaches. 


\section{CONCLUSIONS}

The implementation of PrEP has had significant success in reducing the transmission of HIV in the US, and helps to mitigate risk in groups disproportionately affected by HIV [9, 12, 13, 17, 93, 109], including PWID [12]. While F/TDF has been demonstrated to reduce the risk of HIV infection in PWID [12], modeling suggests that both regimens could provide rapid and lasting protection in this population [110], although we note that F/TAF and F/TDF are not yet approved for this indication.

PrEP uptake rates are suboptimal. There are many reasons behind low PrEP uptake rates, but one barrier cited by individuals has been concern over its long-term safety effects [111]. Adherence to daily PrEP medication may also be impacted by long-term safety concerns or experience of AEs [112]. Lack of adherence may explain why the real-world effectiveness of PrEPs does not always match the efficacy levels observed in clinical trials. Due to adherence concerns, some PrEP users and providers have turned to off-label alternatives to daily dosing, such as on-demand PrEP regimens [83]. Although not appropriate for all patients, ondemand PrEP could be an option allowing further choice for some MSM.

Compounding barriers around safety, the evidence shows that current PrEP users are not all 'young, otherwise healthy' individuals: many are older, have pre-existing medical conditions, or have behavioral risk factors affecting renal and bone health. While for some patients the longestablished F/TDF and the newer F/TAF may both constitute safe and effective PrEP options, for other groups the introduction of F/TAF, with its improved bone and renal safety profile, provides a valuable alternative. It represents an additional step toward personalization of PrEP depending on the individual's broader health status and preferences. As such, F/TAF may help to begin to address the disproportionately low uptake of PrEP among certain populations such as ethnic minorities. In particular, F/TAF may be the medication of choice for populations of cisgender men and transgender women at risk of HIV who are also at risk of developing osteoporosis or renal disease.

The robust safety profile of F/TAF compared with F/TDF may be advantageous in settings where access to in-person visits is limited (e.g., in rural areas, or due to COVID-19-related safety guidelines) [113]. PrEP programs, as well as HIV testing and treatment, have faced considerable disruption as a result of the pandemic, and telemedicine has gained more attention as having an important role. Notably, the safety profile of F/TAF for individuals with renal- and bone-related risk factors may reduce the need for patients to attend clinics in person (although HIV testing would still be necessary). Clinicians should thus consider whether F/TAF may be a safer option when implementing PrEP in a virtual setting.

Age, comorbidities, tobacco smoking, substance use, concomitant medications, race/ethnicity, mental health, family history, and lifestyle should all be considered before initiating any medication, including PrEP. While each factor individually may be insufficient to drive choice of a PrEP medication, taken together, these factors should be considered as part of the 'bigger picture' of the individual's current health, lifestyle, and medical history. It is possible that cost differences between the PrEP options described could be a consideration for HIV prevention programs, and cost-effective analyses should be investigated for current and emerging PrEP options in future studies. Nevertheless, with HIV prevention, as with many other biomedical interventions, providers should consider how the choice of a medication could contribute to or exacerbate other risk factors in a patient's life. As a result, the approach to PrEP should become increasingly individualized and patient centered as more options become available.

\section{ACKNOWLEDGEMENTS}

Funding. Funding for the journal's Rapid Service Fee was provided by Gilead Sciences (Foster City, CA, USA).

Medical Writing, Editorial, and Other Assistance. Medical writing support, including 
development of a draft outline and subsequent drafts in consultation with the authors, collating author comments, copyediting, fact checking, and referencing, was provided by Emma McConnell, PhD, and Josh Lilly, PhD, at Aspire Scientific Limited (Bollington, UK). This assistance was funded by Gilead Sciences (Foster City, CA, USA).

Authorship. All authors meet the International Committee of Medical Journal Editors (ICMJE) criteria for authorship of this article, take responsibility for the integrity of the work as a whole, and have given their approval for publication of the final version.

Disclosures. Sheldon D. Fields received honoraria for key opinion leader advisory board participation from Gilead Sciences. Elyse Tung received honoraria for advisory board and speaker bureau participation from Gilead Sciences.

Compliance with Ethics Guidelines. This article is based on previously conducted studies and does not contain any studies with human participants or animals performed by any of the authors.

Open Access. This article is licensed under a Creative Commons Attribution-NonCommercial 4.0 International License, which permits any non-commercial use, sharing, adaptation, distribution and reproduction in any medium or format, as long as you give appropriate credit to the original author(s) and the source, provide a link to the Creative Commons licence, and indicate if changes were made. The images or other third party material in this article are included in the article's Creative Commons licence, unless indicated otherwise in a credit line to the material. If material is not included in the article's Creative Commons licence and your intended use is not permitted by statutory regulation or exceeds the permitted use, you will need to obtain permission directly from the copyright holder. To view a copy of this licence, visit http:// creativecommons.org/licenses/by-nc/4.0/.

\section{REFERENCES}

1. Centers for Disease Control and Prevention. HIV surveillance report, 2018 (updated); vol. 31. 2020. https://www.cdc.gov/hiv/pdf/library/reports/ surveillance/cdc-hiv-surveillance-report-2018updated-vol-31.pdf. Accessed 23 Sept 2020.

2. Desai M, Field N, Grant R, McCormack S. Recent advances in pre-exposure prophylaxis for HIV. BMJ. 2017;359:j5011.

3. HIV.gov. What is ending the HIV epidemic: a plan for America. 2020. https://www.hiv.gov/federalresponse/ending-the-hiv-epidemic/overview. Accessed 23 Sept 2020.

4. Khalili J, Landovitz RJ. HIV preexposure prophylaxis-the role of primary care clinicians in ending the HIV epidemic. JAMA Intern Med. 2020;180: 126-30.

5. Grant RM, Anderson PL, McMahan V, et al. Uptake of pre-exposure prophylaxis, sexual practices, and HIV incidence in men and transgender women who have sex with men: a cohort study. Lancet Infect Dis. 2014;14:820-9.

6. Liu AY, Cohen SE, Vittinghoff E, et al. Preexposure prophylaxis for HIV infection integrated with municipal- and community-based sexual health services. JAMA Intern Med. 2016;176:75-84.

7. McCormack S, Dunn DT, Desai M, et al. Pre-exposure prophylaxis to prevent the acquisition of HIV-1 infection (PROUD): effectiveness results from the pilot phase of a pragmatic open-label randomised trial. Lancet. 2016;387:53-60.

8. Centers for Disease Control and Prevention. Effectiveness of prevention strategies to reduce the risk of acquiring or transmitting HIV. 2019. https:// www.cdc.gov/hiv/risk/estimates/ preventionstrategies.html\#anchor_1562942347. Accessed 23 Sept 2020.

9. Sullivan PS, Smith DK, Mera-Giler R, et al. The impact of pre-exposure prophylaxis with TDF/FTC on HIV diagnoses, 2012-2016, United States. Abstract 13004. Presented at 22nd International AIDS Conference 2018. Amsterdam, The Netherlands.

10. US Food and Drug Administration. Descovy ${ }^{\circledR}$ (emtricitabine and tenofovir alafenamide) prescribing information 2019. https://www.gilead.com/-/ media/files/pdfs/medicines/hiv/descovy/descovy_ pi.pdf. Accessed 23 Sept 2020.

11. US Food and Drug Administration. Truvada ${ }^{\circledR}$ (emtricitabine/tenofovir disoproxil fumarate) 
prescribing information. 2020. https://www. accessdata.fda.gov/drugsatfda_docs/label/2018/ 021752s055lbl.pdf. Accessed 23 Sept 2020.

12. Choopanya K, Martin M, Suntharasamai P, et al. Antiretroviral prophylaxis for HIV infection in injecting drug users in Bangkok, Thailand (the Bangkok Tenofovir Study): a randomised, doubleblind, placebo-controlled phase 3 trial. Lancet. 2013;381:2083-90.

13. Grant RM, Lama JR, Anderson PL, et al. Preexposure chemoprophylaxis for HIV prevention in men who have sex with men. N Engl J Med. 2010;363: 2587-99.

14. Mayer KH, Molina JM, Thompson MA, et al. Emtricitabine and tenofovir alafenamide vs. emtricitabine and tenofovir disoproxil fumarate for HIV pre-exposure prophylaxis (DISCOVER): primary results from a randomised, double-blind, multicentre, active-controlled, phase 3, non-inferiority trial. Lancet. 2020;396:239-54.

15. Baeten JM, Donnell D, Ndase P, et al. Antiretroviral prophylaxis for HIV prevention in heterosexual men and women. N Engl J Med. 2012;367:399-410.

16. Hosek SG, Landovitz RJ, Kapogiannis B, et al. Safety and feasibility of antiretroviral preexposure prophylaxis for adolescent men who have sex with men aged 15 to 17 years in the United States. JAMA Pediatr. 2017;171:1063-71.

17. Ogbuagu O, Podzamczer D, Salazar L, et al. Longerterm safety of F/TAF and F/TDF for HIV PrEP: DISCOVER trial week-96 results. Presentation O-08. Presented at Conference on Retroviruses and Opportunistic Infections 2020 (online).

18. Martin M, Vanichseni S, Suntharasamai P, et al. Renal function of participants in the Bangkok tenofovir study-Thailand, 2005-2012. Clin Infect Dis. 2014;59:716-24.

19. Cooper RD, Wiebe N, Smith N, Keiser P, Naicker S, Tonelli $M$. Systematic review and meta-analysis: renal safety of tenofovir disoproxil fumarate in HIVinfected patients. Clin Infect Dis. 2010;51:496-505.

20. Baranek B, Wang S, Cheung AM, Mishra S, Tan DH. The effect of tenofovir disoproxil fumarate on bone mineral density: a systematic review and metaanalysis. Antivir Ther. 2020;25:21-32.

21. Mills A, Crofoot G Jr, McDonald C, et al. Tenofovir alafenamide versus tenofovir disoproxil fumarate in the first protease inhibitor-based single-tablet regimen for initial HIV-1 therapy: a randomized phase 2 study. J Acquir Immune Defic Syndr. 2015;69: 439-45.
22. Millan J, Pinto X, Munoz A, et al. Lipoprotein ratios: Physiological significance and clinical usefulness in cardiovascular prevention. Vasc Health Risk Manag. 2009;5:757-65.

23. Campbell T, Clarke A, Trottier B, et al. Safety and efficacy of F/TAF and F/TDF for PrEP in DISCOVER participants taking F/TDF for PrEP at baseline. Presented at IDWeek 2020 (online).

24. Malhotra R, Ostbye T, Riley CM, Finkelstein EA. Young adult weight trajectories through midlife by body mass category. Obesity (Silver Spring). 2013;21:1923-34.

25. Wing RR, Espeland MA, Tate DF, et al. Weight gain over 6 years in young adults: the study of novel approaches to weight gain prevention randomized trial. Obesity. 2020;28:80-8.

26. Centers for Disease Control and Prevention. Preexposure prophylaxis for the prevention of HIV infection in the United States-2017 update. Clinical practice guideline. 2017. https://www.cdc.gov/ hiv/pdf/risk/prep/cdc-hiv-prep-guidelines-2017.pdf. Accessed 23 Sept 2020.

27. Hess KL, Hu X, Lansky A, Mermin J, Hall HI. Lifetime risk of a diagnosis of HIV infection in the United States. Ann Epidemiol. 2017;27:238-43.

28. Becasen JS, Denard CL, Mullins MM, Higa DH, Sipe TA. Estimating the prevalence of HIV and sexual behaviors among the US transgender population: a systematic review and meta-analysis, 2006-2017. Am J Public Health. 2019;109:e1-8.

29. Pellowski JA, Kalichman SC, Matthews KA, Adler N. A pandemic of the poor: social disadvantage and the U.S. HIV epidemic. Am Psychol. 2013;68: 197-209.

30. Centers for Disease Control and Prevention. Chronic kidney disease surveillance system-United States. 2019. https://www.cdc.gov/ kidneydisease/pdf/2019_National-Chronic-KidneyDisease-Fact-Sheet.pdf. Accessed 23 Sept 2020.

31. Inker LA, Astor BC, Fox CH, et al. KDOQI US commentary on the 2012 KDIGO clinical practice guideline for the evaluation and management of CKD. Am J Kidney Dis. 2014;63:713-35.

32. Centers for Disease Control and Prevention. Estimates of diabetes and its burden in the United States. 2020. https://www.cdc.gov/diabetes/pdfs/ data/statistics/national-diabetes-statistics-report. pdf. Accessed 23 Sept 2020.

33. Benjamin EJ, Muntner P, Alonso A, et al. Heart disease and stroke statistics-2019 update: a report 
from the American Heart Association. Circulation. 2019;139:e56-528.

34. US Renal Data System. 2019 annual data report: Epidemiology of kidney disease in the United States. 2019. https://www.usrds.org/media/2371/ 2019-executive-summary.pdf. Accessed 23 Sept 2020.

35. Lora CM, Daviglus ML, Kusek JW, et al. Chronic kidney disease in United States Hispanics: a growing public health problem. Ethn Dis. 2009;19:466-72.

36. Centers for Disease Control and Prevention. National diabetes statistics report 2020. https:// www.cdc.gov/diabetes/pdfs/data/statistics/ national-diabetes-statistics-report.Pdf. Accessed 23 Sept 2020.

37. Nitta K, Okada K, Yanai M, Takahashi S. Aging and chronic kidney disease. Kidney Blood Press Res. 2013;38:109-20.

38. Delanaye P, Glassock RJ, Pottel H, Rule AD. An agecalibrated definition of chronic kidney disease: rationale and benefits. Clin Biochem Rev. 2016;37: $17-26$.

39. National Institute on Alcohol Abuse and Alcoholism. Alcohol alert. 2010. https://pubs.niaaa.nih. gov/publications/AA80/AA80.pdf. Accessed $23 \mathrm{Sept}$ 2020 .

40. Solomon TM, Halkitis PN, Moeller RW, Pappas MK. Levels of methamphetamine use and addiction among gay, bisexual, and other men who have sex with men. Addict Res Theory. 2012;20:21-9.

41. McCabe SE, West BT, Hughes TL, Boyd CJ. Sexual orientation and substance abuse treatment utilization in the United States: results from a national survey. J Subst Abuse Treat. 2013;44:4-12.

42. Reback CJ, Fletcher JB, Shoptaw S, Grella CE. Methamphetamine and other substance use trends among street-recruited men who have sex with men, from 2008 to 2011. Drug Alcohol Depend. 2013;133:262-5.

43. Mansoor K, Kheetan M, Shahnawaz S, et al. Systematic review of nephrotoxicity of drugs of abuse, 2005-2016. BMC Nephrol. 2017;18:379.

44. Orth SR, Hallan SI. Smoking: a risk factor for progression of chronic kidney disease and for cardiovascular morbidity and mortality in renal patients-absence of evidence or evidence of absence? Clin J Am Soc Nephrol. 2008;3:226-36.

45. Cullen KA, Ambrose BK, Gentzke AS, Apelberg BJ, Jamal A, King BA. Notes from the field: Use of electronic cigarettes and any tobacco product among middle and high school students-United States, 2011-2018. Morb Mortal Wkly Rep. 2018;67: 1276-7.

46. Drummond C, Alexander LEC, Tian J. Chronic electronic cigarette vapor inhalation induces renal injury and functional decline in female mice. FASEB J. 2017;31:1.

47. Hwang YJ, Dixon SN, Reiss JP, et al. Atypical antipsychotic drugs and the risk for acute kidney injury and other adverse outcomes in older adults: a population-based cohort study. Ann Intern Med. 2014;161:242-8.

48. Remien RH, Stirratt MJ, Nguyen N, Robbins RN, Pala AN, Mellins CA. Mental health and HIV/AIDS: the need for an integrated response. AIDS. 2019;33: 1411-20.

49. Bartoli E. Adverse effects of drugs on the kidney. Eur J Intern Med. 2016;28:1-8.

50. Tomlinson LA, Abel GA, Chaudhry AN, et al. ACE inhibitor and angiotensin receptor-II antagonist prescribing and hospital admissions with acute kidney injury: a longitudinal ecological study. PLoS One. 2013;8:e78465.

51. Glezerman IG, Jaimes EA. Chapter 11. Chemotherapy and kidney injury. American Society of Nephrology [Onco-Nephrology Curriculum]. New York: American Society of Nephrology; 2016.

52. Patel JB, Sapra A. Nephrotoxic medications. Treasure Island: StatPearls; 2020.

53. Naughton CA. Drug-induced nephrotoxicity. Am Fam Phys. 2008;78:743-50.

54. Feldman MB, Meyer IH. Eating disorders in diverse lesbian, gay, and bisexual populations. Int $\mathrm{J}$ Eat Disord. 2007;40:218-26.

55. Li Cavoli G, Mule G, Rotolo U. Renal involvement in psychological eating disorders. Nephron Clin Pract. 2011;119:c338-41 (discussion c41).

56. McManus H, Drak D, Heron JE, et al. Renal impairment in a pre-exposure prophylaxis implementation cohort in Australia. Poster P-S05. Presented at Conference on Retroviruses and Opportunistic Infections 2020 (online).

57. Tang EC, Vittinghoff E, Anderson PL, et al. Changes in kidney function associated with daily tenofovir disoproxil fumarate/emtricitabine for HIV preexposure prophylaxis use in the United States demonstration project. J Acquir Immune Defic Syndr. 2018;77:193-8. 
58. Mills A, Workowski K, Campbell T, et al. Renal outcomes for participants taking F/TAF vs. F/TDF for HIV PrEP in the DISCOVER trial. Open Forum Infect Dis. 2019;6(Suppl 2):S64.

59. Gandhi M, Glidden DV, Mayer K, et al. Association of age, baseline kidney function, and medication exposure with declines in creatinine clearance on pre-exposure prophylaxis: an observational cohort study. Lancet HIV. 2016;3:e521-8.

60. Wright NC, Looker AC, Saag KG, et al. The recent prevalence of osteoporosis and low bone mass in the United States based on bone mineral density at the femoral neck or lumbar spine. J Bone Miner Res. 2014;29:2520-6.

61. Loud KJ, Gordon CM. Adolescent bone health. Arch Pediatr Adolesc Med. 2006;160:1026-32.

62. Bowles SK. Drug-induced osteoporosis. In: PSAP women's and men's health. Lenexa: American College of Clinical Pharmacy; 2010. p. 203-24.

63. Boyanov MA. Bone development in children and adolescents. In: Kumanov P, Agarwal A, editors. Puberty: Physiology and Abnormalities. Cham: Springer; 2016. p. 77-94.

64. Kranioti EF, Bonicelli A, García-Donas JG. Bonemineral density: clinical significance, methods of quantification and forensic applications. Res Rep Forensic Med Sci. 2019;9:9-21.

65. Hodges JK, Cao S, Cladis DP, Weaver CM. Lactose intolerance and bone health: the challenge of ensuring adequate calcium intake. Nutrients. 2019;11:718.

66. Nicklas TA, Qu H, Hughes SO, et al. Self-perceived lactose intolerance results in lower intakes of calcium and dairy foods and is associated with hypertension and diabetes in adults. Am J Clin Nutr. 2011;94:191-8.

67. Pampel FC, Krueger PM, Denney JT. Socioeconomic disparities in health behaviors. Annu Rev Sociol. 2010;36:349-70.

68. Solmi M, Veronese N, Correll CU, et al. Bone mineral density, osteoporosis, and fractures among people with eating disorders: a systematic review and meta-analysis. Acta Psychiatr Scand. 2016;133: 341-51.

69. Naessén S, Carlström K, Glant R, Jacobsson H, Hirschberg AL. Bone mineral density in bulimic women-influence of endocrine factors and previous anorexia. Eur J Endocrinol. 2006;155:245-51.
70. Kanis JA, Johansson H, Johnell O, et al. Alcohol intake as a risk factor for fracture. Osteoporos Int. 2005;16:737-42.

71. Kim EY, Kwon DH, Lee BD, et al. Frequency of osteoporosis in 46 men with methamphetamine abuse hospitalized in a National Hospital. Forensic Sci Int. 2009;188:75-80.

72. Al-Bashaireh AM, Haddad LG, Weaver M, Chengguo $\mathrm{X}$, Kelly DL, Yoon S. The effect of tobacco smoking on bone mass: an overview of pathophysiologic mechanisms. J Osteoporos. 2018;2018: 1206235 .

73. Buckley L, Guyatt G, Fink HA, et al. 2017 American College of Rheumatology guideline for the prevention and treatment of glucocorticoid-induced osteoporosis. Arthritis Rheumatol. 2017;69: 1521-37.

74. Curtis JR, Westfall AO, Allison J, et al. Populationbased assessment of adverse events associated with long-term glucocorticoid use. Arthritis Rheum. 2006;55:420-6.

75. Overman RA, Yeh J-Y, Deal CL. Prevalence of oral glucocorticoid usage in the United States: a general population perspective. Arthritis Care Res (Hoboken). 2013;65:294-8.

76. Panday K, Gona A, Humphrey MB. Medication-induced osteoporosis: screening and treatment strategies. Ther Adv Musculoskelet Dis. 2014;6: 185-202.

77. Wohl D, Ruane P, Hosek S, et al. Bone safety outcomes with F/TAF vs. F/TDF for PrEP in the DISCOVER trial. Abstract 1288. Presented at IDWeek 2019. Washington (DC).

78. Liu AY, Vittinghoff E, Sellmeyer DE, et al. Bone mineral density in HIV-negative men participating in a tenofovir pre-exposure prophylaxis randomized clinical trial in San Francisco. PLoS One. 2011;6: e23688.

79. Mulligan K, Glidden DV, Anderson PL, et al. Effects of emtricitabine/tenofovir on bone mineral density in HIV-negative persons in a randomized, doubleblind, placebo-controlled trial. Clin Infect Dis. 2015;61:572-80.

80. Kasonde M, Niska RW, Rose C, et al. Bone mineral density changes among HIV-uninfected young adults in a randomised trial of pre-exposure prophylaxis with tenofovir-emtricitabine or placebo in Botswana. PLoS One. 2014;9:e90111.

81. Mirembe BG, Kelly CW, Mgodi N, et al. Bone mineral density changes among young, healthy African women receiving oral tenofovir for HIV 
preexposure prophylaxis. J Acquir Immune Defic Syndr. 2016;71:287-94.

82. Scott H, Vittinghoff E, Irvin R, et al. Development and validation of the personalized sexual health promotion (SexPro) HIV risk prediction model for men who have sex with men in the United States. AIDS Behav. 2020;24:274-83.

83. Molina JM, Charreau I, Spire B, et al. Efficacy, safety, and effect on sexual behaviour of on-demand preexposure prophylaxis for HIV in men who have sex with men: an observational cohort study. Lancet HIV. 2017;4:e402-10.

84. Molina J-M, Capitant C, Spire B, et al. On-demand preexposure prophylaxis in men at high risk for HIV-1 infection. N Engl J Med. 2015;373:2237-46.

85. Antoni G, Tremblay C, Delaugerre C, et al. On-demand pre-exposure prophylaxis with tenofovir disoproxil fumarate plus emtricitabine among men who have sex with men with less frequent sexual intercourse: a post-hoc analysis of the ANRS IPERGAY trial. Lancet HIV. 2020;7:e113-20.

86. Wheeler DP, Fields SD, Beauchamp G, et al. Preexposure prophylaxis initiation and adherence among Black men who have sex with men (MSM) in three US cities: results from the HPTN 073 study. J Int AIDS Soc. 2019;22:e25223.

87. World Health Organization. What's the $2+1+1$ ? Event-driven oral pre-exposure prophylaxis to prevent HIV for men who have sex with men: update to WHO's recommendation on oral PrEP. 2019. https://apps.who.int/iris/bitstream/handle/10665/ 325955/WHO-CDS-HIV-19.8-eng.pdf?ua=1. Accessed 16 Nov 2020.

88. Winston A, Amin J, Mallon P, et al. Minor changes in calculated creatinine clearance and anion-gap are associated with tenofovir disoproxil fumarate-containing highly active antiretroviral therapy. HIV Med. 2006;7:105-11.

89. Mugwanya KK, Wyatt C, Celum C, et al. Changes in glomerular kidney function among HIV-1-uninfected men and women receiving emtricitabinetenofovir disoproxil fumarate preexposure prophylaxis: a randomized clinical trial. JAMA Intern Med. 2015;175:246-54.

90. Solomon MM, Lama JR, Glidden DV, et al. Changes in renal function associated with oral emtricitabine/ tenofovir disoproxil fumarate use for HIV pre-exposure prophylaxis. AIDS. 2014;28:851-9.

91. Otaki Y, Watanabe T, Shishido T, et al. The impact of renal tubular damage, as assessed by urinary beta2-microglobulin-creatinine ratio, on cardiac prognosis in patients with chronic heart failure. Circ Heart Fail. 2013;6:662-8.

92. Pallet N, Chauvet S, Chasse JF, et al. Urinary retinol binding protein is a marker of the extent of interstitial kidney fibrosis. PLoS One. 2014;9:e84708.

93. Cespedes M, Majeed S, Prins M, et al. DISCOVER: no effect of hormones on F/TAF or F/TDF PK, efficacy \& safety in transwomen. Poster P-S08. Presented at Conference on Retroviruses and Opportunistic Infections 2020 (online).

94. Hosek SG, Rudy B, Landovitz R, et al. An HIV preexposure prophylaxis demonstration project and safety study for young MSM. J Acquir Immune Defic Syndr. 2017;74:21-9.

95. Havens PL, Perumean-Chaney SE, Patki A, et al. Changes in bone mass after discontinuation of preexposure prophylaxis with tenofovir disoproxil fumarate/emtricitabine in young men who have sex with men: extension phase results of adolescent trials network protocols 110 and 113. Clin Infect Dis. 2020;70:687-91.

96. Wohl D, Ruane P, Hosek S, et al. Bone safety outcomes with F/TAF vs. F/TDF for PrEP in the DISCOVER trial. Open Forum Infect Dis. 2019;6(Suppl 2):S464.

97. Fields J, Go JT, Schulze KS. Pill properties that cause dysphagia and treatment failure. Curr Ther Res Clin Exp. 2015;77:79-82.

98. Dorman RM, Sutton SH, Yee LM. Understanding HIV-related pill aversion as a distinct barrier to medication adherence. Behav Med. 2019;45: 294-303.

99. Rael CT, Martinez M, Giguere R, et al. Barriers and facilitators to oral PrEP use among transgender women in New York City. AIDS Behav. 2018;22: 3627-36.

100. U.S. Department of Health and Human Services. Emtricitabine/tenofovir disoproxil fumarate. 2020. https://aidsinfo.nih.gov/drugs/406/truvada/8/ professional. Accessed 23 Sept 2020.

101. Gilead Sciences Inc. Descovy: emtricitabine 200 $\mathrm{mg} /$ tenofovir alafenamide $25 \mathrm{mg}$ tablets for preexposure prophylaxis. 2020. https://www. descovyhcp.com/Content/documents/descovy_ daytracker_fact_sheet.pdf. Accessed 23 Sept 2020.

102. Conn VS, Ruppar TM, Chan KC, Dunbar-Jacob J, Pepper GA, De Geest S. Packaging interventions to increase medication adherence: systematic review and meta-analysis. Curr Med Res Opin. 2015;31: $145-60$. 
103. Matthews RP, Barnett SE, Patel M, Zhu W, Fillgrove L, Haspeslagh L. First-in-human trial of MK-8591eluting implants demonstrates concentrations suitable for HIV prophylaxis for at least one year. Abstract TUAC0401LB. Presented at IAS 2019. Mexico City, Mexico.

104. Injectable cabotegravir effective as HIV PrEP when given every 2 months. https://www.healio.com/ news/infectious-disease/20200518/injectablecabotegravir-effective-as-hiv-prep-when-givenevery-2-months. Accessed 29 Oct 2020.

105. The HIV Prevention Trials Network. HPTN 084 FAQ. https://www.hptn.org/sites/default/files/inlinefiles/HPTN\%20084\%20DSMB\%20FAQ_V1.0_ 8Nov2020_0.pdf. Accessed 30 Nov 2020.

106. Sok D, Burton DR. Recent progress in broadly neutralizing antibodies to HIV. Nat Immunol. 2018;19: 1179-88.

107. Barin F, Braibant M. HIV-1 antibodies in prevention of transmission. Curr Opin HIV AIDS. 2019;14: 273-8.

108. Huang Y, Karuna S, Carpp LN, et al. Modeling cumulative overall prevention efficacy for the
VRC01 phase $2 b$ efficacy trials. Hum Vaccin Immunother. 2018;14:2116-27.

109. Krakower DS, Daskalakis DC, Feinberg J, Marcus JL. Tenofovir alafenamide for HIV preexposure prophylaxis: what can we DISCOVER about its true value? Ann Intern Med. 2020;172:281-2.

110. Garrett KL, Chen J, Maas BM, et al. A pharmacokinetic/pharmacodynamic model to predict effective HIV prophylaxis dosing strategies for people who inject drugs. J Pharmacol Exp Ther. 2018;367: 245-51.

111. Tetteh RA, Yankey BA, Nartey ET, Lartey M, Leufkens HG, Dodoo AN. Pre-exposure prophylaxis for HIV prevention: safety concerns. Drug Saf. 2017;40:273-83.

112. Sidebottom D, Ekström AM, Strömdahl S. A systematic review of adherence to oral pre-exposure prophylaxis for HIV-how can we improve uptake and adherence? BMC Infect Dis. 2018;18:581.

113. American Public Health Association. COVIDGuidance.org. https://www.apha.org/topics-and-issues/ communicable-disease/coronavirus/guidance. Accessed 30 Nov 2020. 